


\section{Ditko e Franco... dois tempos, duas poéticas visuais e um mesmo problema: a dor e o sofrimento na condição humana ${ }^{1}$}

Resumo

Este trabalho apresenta um estudo comparativo entre duas poéticas visuais diferentes: a de Steve Ditko e a de Edgar Franco. Define o que compreende por poética visual e apresenta dois trabalhos de histórias em quadrinhos, um de cada um dos autores escolhidos. Explicita a origem da construção poética de cada um deles e defende, à luz das contribuições de Stanislav Grof, que elas sejam consideradas como convites para que os leitores possam construir suas próprias poéticas e, assim, elaborar respostas, também eles, aos desafios da condição humana.
1. Texto originalmente apresentado no II Seminário Nacional de Pesquisa em Cultura Visual, de 17 a 19 de junho de 2009, na UFG, Goiania. Publicado no CD-Rom do Congresso, no ano de 20o9, sendo o ISSN: 1983-1919.

Palavras-chave: Steve Ditko, Edgar Franco, histórias em quadrinhos 


\begin{abstract}
:
The present study portrays a comparative approach between two different visual poetics: Steve Ditko's and Edgar Franco's. It defines an understanding of visual poetics and presents two studies on comic books, referring to the aforementioned authors. It reveals the origin of its poetic foundations and supports, in the light of the contributions made by Stanislav Grof, that such comic books may pave the way for the reader's own poetic conceptions, so that he/she can somehow delve into the challenges of human nature.
\end{abstract}




\section{Introdução}

Recentemente, quando estava lendo um trabalho de Douglas Wolk $^{2}$, mais especificamente o capítulo sobre Steve Ditko ${ }^{3}$, embora não conhecesse a história do Homem-Aranha ao qual o texto se referia, tive a súbita impressão que a descrição que o autor fazia, de determinada seqüência visual, aproximava-se muito dos diferentes sentimentos que um feto humano tem ao nascer pelo processo do parto normal. Lembrava dos estudos de Stanislav Grof ${ }^{4}$ em torno do campo perinatal ${ }^{5}$ e suas implicações para o processo humano de desenvolvimento. A descrição de Wolk, sobre a seqüência desenhada por Ditko, é a seguinte:

"O que há de grandioso em toda aquela seqüência depende da linguagem corporal - Ditko não utilizou expressões faciais, uma vez que o Homem-Aranha tem o rosto coberto por inteiro pela máscara. Nela há apenas o Homem-Aranha e uma grande peça de metal (com água pingando sobre ele e aumentando mais e mais sua intensidade em cada quadro da seqüência), mas no curso de cinco páginas, Ditko nos mostra desespero, esperança, exaustão, culpa, ódio, determinação, e finalmente, vitória dramática. É emocionante apenas de olhar." (Wolk, 2007, p. 158)

A primeira página da sequência desenhada por Ditko, a que Wolk se refere, é a mostrada na figura o1:

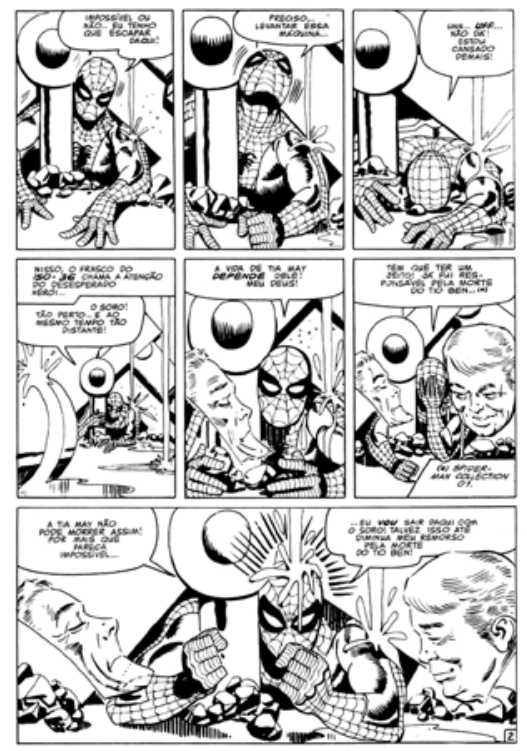

Figura o1 - Primeira página da sequência de "Capítulo Final, desenhada por Steve Ditko, destacada por Wolk
2. Reading Comics: How graphic novels work and what they mean. (2007)

3. Chapter 8, Steve Ditko: A Is A.

4. Pesquisador nascido em Praga, mas radicado nos Estados Unidos da América desde a década de 1960, que se tornou conhecido por seus trabalhos de pesquisa em torno da consciência humana, em seus estados hilotrópico (direcionados à matéria) e holotrópico (direcionados à totalidade). Autor de "Além do Cérebro: nascimento, morte e transcendência em psicoterapia" (1987) e de "A mente holotrópica: novos conhecimentos sobre a psicologia e pesquisa da consciência". Rio de Janeiro, Rocco, 1994. Criador, com Christina Grof, da Respiração Holotrópica, um método de auto-exploração que combina respiração (hiperventilação), música iniciática e trabalho corporal localizado como uma forma de acessar os níveis mais profundos da consciência.

5. Perinatal: Peri (em torno), natal (nascimento), portanto em torno do nascimento. Perinatal, assim, refere-se aos eventos que Grof estudou durante o processo de gestação, no período que antecede o parto normal, durante o parto normal e na sua imediata conclusão. 
6. MARVEL COMICS - As primeiras histórias em quadrinhos do Homem-Aranha, no. 8 (Spider-Man Collection), publicado pela Editora Abril em 1997. Este volume traz as histórias de "Amazing Spider-Man" das revistas de números 32 a 36, publicadas nos EUA em 1966. A história em questão foi publicada na revista no. 33, intitulada

"O Capítulo Final, com roteiro de Stan Lee; argumento e arte de Steve Ditko.

7. A discussão sobre o póshumano é de nossa humanidade contemporânea e é impulsionada pelo nosso estupendo desenvolvimento tecnológico. Edgar Franco a incorporou tanto em sua obra como pesquisador, vide sua tese de doutorado, como em sua obra

ficcional nos quadrinhos, $\mathrm{da}$ qual exemplos primorosos são a história em quadrinhos "Parto" $e$ o álbum "BioCyberDrama".
O que me remetia a Grof era a seqüência de palavras utilizadas por Wolk para descrever os sentimentos do Homem-Aranha: desespero, esperança, exaustão, culpa, ódio, determinação e vitória dramática. Estes sentimentos aproximam-se muito daqueles que um feto vivencia em seu processo de deixar a vida intra-uterina, processo no qual, de acordo com Grof, aprende uma série coisas que permanecem consigo, ainda que em nível inconsciente, mas que serão determinantes sobre a maneira como aquele ser humano, que assim nasce, enfrentará a vida pós-uterina.

Consegui localizar a história completa publicada no Brasil ${ }^{6}$ e ao visualizar as imagens da seqüência, desenhada por Ditko, minha leitura confirmava a semelhança entre a situação vivida pelo Homem-Aranha e a situação vivida pelo feto no momento da saída do útero, com a passagem pelo canal do nascimento. A pesada peça de metal e o espaço diminuto faziam às vezes do útero e do canal do nascimento; o esforço empreendido pelo Homem-Aranha para dali sair assemelhava-se ao esforço empreendido, pelo feto e pela mãe, para o sucesso do nascimento; nos dois casos era uma luta entre a vida e a morte; os dois casos implicavam em juntar todas as forças para continuar a viver, para "re-nascer".

Nesta minha "viagem" pessoal por aquela visualidade lembreime da história em quadrinhos de Edgar Franco, intitulada "Parto" (2007), e fiquei pensando que havia ali duas poéticas visuais que, cada uma a seu modo, falavam dos processos de nascer, do sofrimento e de suas implicações para a vida humana e póshumana ${ }^{7}$. A continuidade desta reflexão é o que apresento neste artigo, preocupado em mostrar que a experiência da condição humana - experiência a um só tempo de grandeza e miséria - éa grande fonte de onde brotam diferentes poéticas visuais. Estas, por sua vez, criadas por diferentes artistas, neste caso em especial do campo das histórias em quadrinhos, são importantes convites para que os seres humanos, que com elas fazem contato, possam construir suas próprias poéticas, visuais ou não, que, como sugere Costa (2002), são uma forma que temos encontrado para enfrentar a dura condição do "despregamento" da natureza ou, numa linguagem metafórica, a perda do "paraíso", que nos faz, a todo o momento, pensar: Quem somos? De onde viemos? O que estamos fazendo aqui? Por que vivemos o que vivemos? Qual o sentido da existência? 


\section{Poéticas Visuais, Políticas, Histórias em \\ Quadrinhos e Pedagogia Cultural}

Uma das raízes possíveis das palavras poético, poética e poesia está em poíesis, do grego antigo, que significa criar, fazer ou como nas palavras de Martins, Picosque e Guerra (1998, p. 24) - a "ação de fazer algo; aquilo que desperta o sentido do belo, que encanta e enleva (...) capacidade de criação, desvelando verdades presentes na natureza e na vida que ficariam submersas sem sua presentificação. Desse modo, o ser humano poetiza sua relação com o mundo".

Também Joel Martins, em seu importante trabalho "Um enfoque fenomenológico do currículo: Educação como poíesis” (1992, p.88-89), explicita o caráter criativo e imaginativo de poíesis:

"Heidegger põe em evidência que "habitamos aquilo que construímos'. Este é, realmente, o sentido do termo 'poesia' quando ele está se referindo à educação, sendo também usado pelo artista que habita aquilo que constrói através de sua imaginação; refere-se, ainda, ao uso da linguagem, das palavras, dos mitos e símbolos. Para os gregos esta construção, o fazer e o habitar, o que foi construído, constitui a poíesis. O termo envolve, necessariamente, uma criação, um pensar, um construir onde o poeta habita. Constitui-se dessa forma um pensar criativo, um habitar. Este habitar é a maneira pela qual os seres mortais estão na terra, desdobrando-se num construir que cultiva as coisas que crescem, assim como envolve a ação de erigir prédios ou edifícios. Vendo-se poíesis como construção, criação, linguagem, símbolos e mitos, poderíamos dizer que tudo o que constitui o falar cotidiano pode acontecer no mundo poético."

A capacidade poética é, pois, aqui compreendida como a possibilidade que nós humanos temos de simbolizar, significar e recriar o mundo, e nossa relação com ele, a partir de nossa imaginação. Sem esta capacidade de poetizar o mundo seríamos seres de pura adaptação e não seres de criação, transformação e mudança. Porque poéticos podemos desejar, sonhar, pensar e criar mundos novos. Por isso é possível falar numa "política dos gestos poéticos". Rubem Alves escreveu uma biografia de Gandhi que tem exatamente este subtítulo: "Mahatma Gandhi: a política dos gestos poéticos" (1983). Alves escreveu o trabalho em primeira pessoa, como se fosse Gandhi mesmo a falar, e em dado momento, referindo-se aos gestos poéticos, coloca na boca do biografado o seguinte: 
8. Conferir, de Thierry Groensteen, "Histórias em quadrinhos: essa desconhecida arte popular". João Pessoa, Marca de Fantasia,
"Compreendi que era destes gestos que nasciam as grandes metamorfoses, dos indivíduos, das comunidades, de povos inteiros. A razão? É que eles atingem o coração. Não existe nenhum outro caminho que nos possa levar à transformação do mundo. E nada há que se lhes compare em poder." (ALVES, 1986, p. 10)

Reconheço a complexidade desta discussão, mas não quero entrar em seus meandros. Neste momento me é suficiente afirmar que uma poética, que nasce da relação imaginativa com o mundo e os outros humanos, é também uma política, pois provoca mudanças nas visões de mundo das pessoas e, conseqüentemente, no modo como se intervém nele e, portanto, favorece a reprodução ou a transformação na forma como o coletivo humano, polis, se organiza. A poética é, assim, uma "poderosa" capacidade humana de criação e intervenção.

Também as histórias em quadrinhos criam poéticas: poéticas visuais. Nascidas, em sua forma mais recente, na perspectiva do entretenimento popular e, por isso mesmo, submetidas durante muito tempo a um grande preconceito, pois a viam como um artefato cultural "menor", de "segunda categoria" - nas últimas décadas estão conquistando espaços privilegiados não apenas nas universidades, mas também nas livrarias, ampliando, inclusive, os gêneros nas quais são elaboradas, sem abandonar sua característica de excelente forma de arte popular ${ }^{8}$. Exemplos recentes da referida ampliação são: "Valsa com Bashir" (2009), o filme, queé um documentário inspirado nos quadrinhos jornalísticos de Joe Sacco e também tem sua versão em histórias em quadrinhos; "Persépolis", a premiada história em quadrinhos da iraniana Marjane Satrapi, que teve sua versão em animação indicada ao Oscar da categoria no ano de 2008.

No campo das histórias em quadrinhos é possível destacar também artistas que se sobressaíram com criativas e poderosas poéticas visuais. A título de exemplo quero lembrar: os EUA com Alex Raymond, Harold Foster, Milton Caniff, Burne Hogart, Will Eisner, Joe kubert, Frank Miller, Art Spiegelman, Bill Sienkiewicz e Joe Sacco; a França com Moebius, Caza e Druillet; a Bélgica com Hergé; a Itália com Hugo Pratt; a Inglaterra com Dave Gibbons; o Japão com Ozamu Tezuka; o Brasil com Flávio Colin, Henfil, Ziraldo, Cláudio Seto, Mozart Couto, os gêmeos Gabriel Bá e Fábio Moon. Isto para não falar de roteiristas como Alan Moore (Watchmen) e Neil Gaiman (Sandman) que têm ajudado a criar, por meio de suas narrativas, significativas poéticas visuais que têm impactado um grande público. 
Como as histórias em quadrinhos estão ligadas também à indústria cultural, então é necessário trazer aqui, desde uma perspectiva da educação escolar, a idéia de Pedagogia Cultural, que tem raízes no pensamento de Henry Giroux e Shirley Steinberg9. Vorraber Costa (2002, p. 144) afirma, referindo-se a Giroux e Steinberg:

"Segundo esses autores, todos os locais da cultura em que o poder se organiza e se exercita, como os programas de TV, filmes, jornais, revistas, brinquedos, catálogos, propagandas, anúncios, videogames, livros, esportes, shoppings centers, entre tantos outros, são espaços que educam, praticando pedagogias culturais que moldam nossa conduta. As pedagogias culturais vão formando a nossa identidade, na medida em que envolvem nosso desejo, capturam nossa imaginação e vão construindo a nossa consciência. Isso significa que há pedagogias culturais e currículos culturais em andamento dentro e fora das instituições educacionais, estruturados de acordo com as forças que regem a dinâmica comercial, política e cultural predominante no mundo contemporâneo".

A observação quanto às pedagogias culturais é importante para ajudar os professores a libertarem-se de conteúdos escolares que se cristalizaram em um formalismo vazio e desprovido de sentido para os estudantes, e assumirem uma postura pedagógica que favoreça a construção de uma postura reflexiva e crítica diante dos produtos culturais oferecidos ao consumo das pessoas na sociedade capitalista, inclusa toda cultura visual. Afirma Giroux (1992, p. 96):

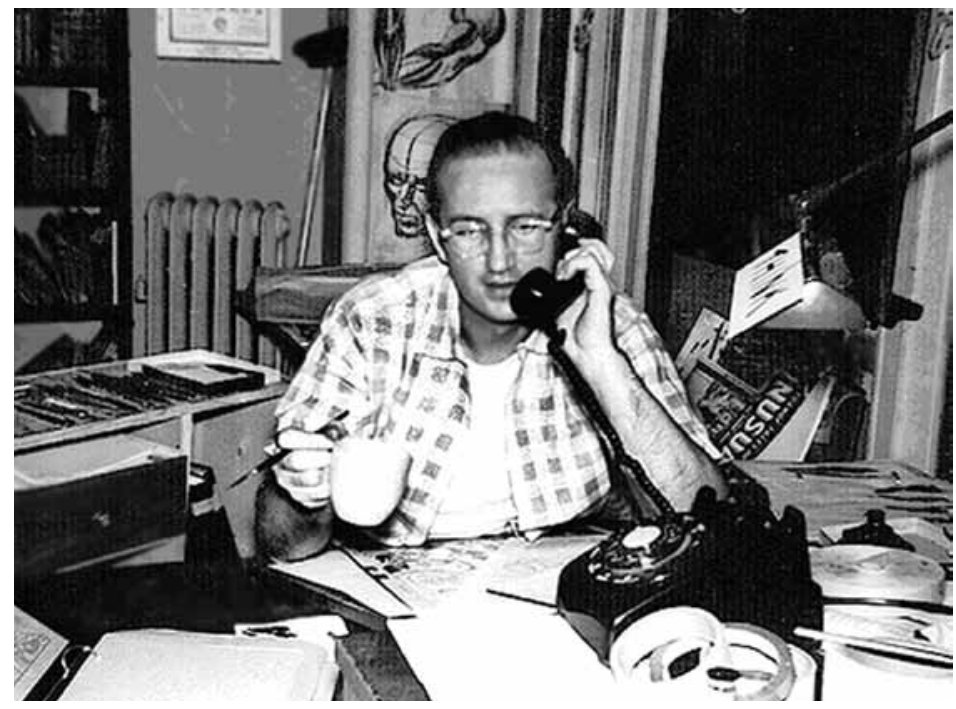

Figura 02 - Steve Ditko em foto de Britt Stanton (reprodução do site www.ditko.comics.org)
9. Conferir: STEINBERG, Shirley (Org.) Cultura Infantil: A construção corporativa da infância. Rio de Janeiro: Civilização Brasileira, 2001. 
10. Escola fundada em 1947 por Silas H. Rhodes e Burne Hogarth, o famoso desenhista de Tarzan. Em 1956 mudou seu nome para School of Visual Arts (S.V.A.). Esta escola existe ainda hoje, tendo boa avaliação entre as escolas de artes nos EUA. Conferir: www. schoolofvisualarts.edu/index.jsp.

11. Além de contribuir para o visual de vários personagens clássicos das histórias em quadrinhos, do qual o HomemAranha é o mais célebre, Steve Ditko criou personagens e enredos que exigiram saber usar bem a linguagem dos quadrinhos. É o caso, por exemplo, do personagem Questão. Não por acaso, Alan Moore, apesar de reconhecer a posição política de direita de Steve Ditko e, portanto, distante da sua - segundo ele próprio uma posição anarquista - tem em Ditko uma referência importante nas histórias em quadrinhos, tanto pela forma como pelo conteúdo. Sua primeira idéia para Watchmen, uma grande releitura do mundo dos heróis, era trabalhar com os personagens criados por

Ditko: Capitão Átomo, Questão e Besouro Azul. Como a idéia não foi aprovada pelos editores responsáveis, então ele criou novos personagens, mas tendo a criação de Ditko como referência. Assim, Dr. Manhattan teve como referência o Capitão Átomo; Rorshach foi baseado em Questão e o Coruja no Besouro Azul. Conferir a entrevista de Alan Moore, em 16/o6/20oo: http://br.geocities.com/ watchmenbrasil/ogmoore.htm.
"De fato, uma política cultural requer o desenvolvimento de pedagogia que seja aberta às histórias, aos sonhos e às experiências que os alunos trazem para a escola. Somente começando por essas formas subjetivas, os educadores críticos poderão desenvolver uma linguagem e um conjunto de práticas que confirmem e engajem a natureza contraditória do capital cultural que constitui o modo como os estudantes produzem os significados que legitimam formas específicas de vida".

A perspectiva aqui é a de que os educadores estejam atentos à vida - própria e coletiva -, às políticas culturais, à cultura visual, às poéticas visuais e ao modo como os alunos/as, a partir da relação entre suas subjetividades e o mundo vivido, têm construído suas próprias narrativas poéticas que marcam a maneira como estão engajando-se no mundo.

\section{A poética visual de Steve Ditko e uma seqüência importante de "O Capítulo final".}

Steve Ditko nasceu em 2 de novembro de 1927, em Johnstown, Estados Unidos. Cursou Desenho na Cartoonists and Illustrators Scho$\mathrm{ol}^{10}$, em Nova York. Começou sua carreira como desenhista em 1953, na revista Black Magic, da Crestwood Publications, desenhando histórias de terror e suspense. Em 1963 criou, juntamente com Stan Lee, o Homem-Aranha. Ditko é o responsável pela criação visual deste personagem e dos elementos básicos de seu universo. Avesso a entrevistas, fotografias e filmagens tem permitido poucos registros de si mesmo. Recentemente, em 2008, foi publicada, nos Estados Unidos, uma obra que resgata os trabalhos que criou ao longo de sua vida profissional: "Strange and Stranger: The world of Steve Ditko”, de Blake Bell, publicada pela FantagraphicsBooks. Na Figura 02 um dos raros registros fotográficos de Steve Ditko:

Embora tenha criado muitas histórias, personagens e universos (o visual da armadura vermelho e dourada do Homem de Ferro, Besouro Azul, Capitão Átomo, Questão, Mr. A, Rastejante, etc.) e tenha contribuído com muitas inovações para a linguagem visual dos quadrinhos ${ }^{11}$, é especialmente sobre o trabalho para "O Capítulo Final" (1997) que eu quero me deter. Ainda que o personagem Homem-Aranha esteja na constelação do universo comercial, há que se ressaltar a autoralidade de Steve Ditko, e também de Stan Lee que originalmente o concebeu, em especial naquele momento, pois é o começo do trabalho com o personagem, isto é, é um momento ainda inicial do processo de 
criação daquele que seria, posteriormente, um grande sucesso de vendagens. Mas, na metade da década de 1960 o personagem está ainda sendo construído e não há, portanto, demasiada constrição por parte das preocupações comerciais, o que deixou Lee e Ditko mais livres em seu processo criativo. As figuras 3 e 4, a seguir, é uma das páginas que Ditko criou para esta história e expressa um pouco da riqueza de sua narrativa e poética visual:
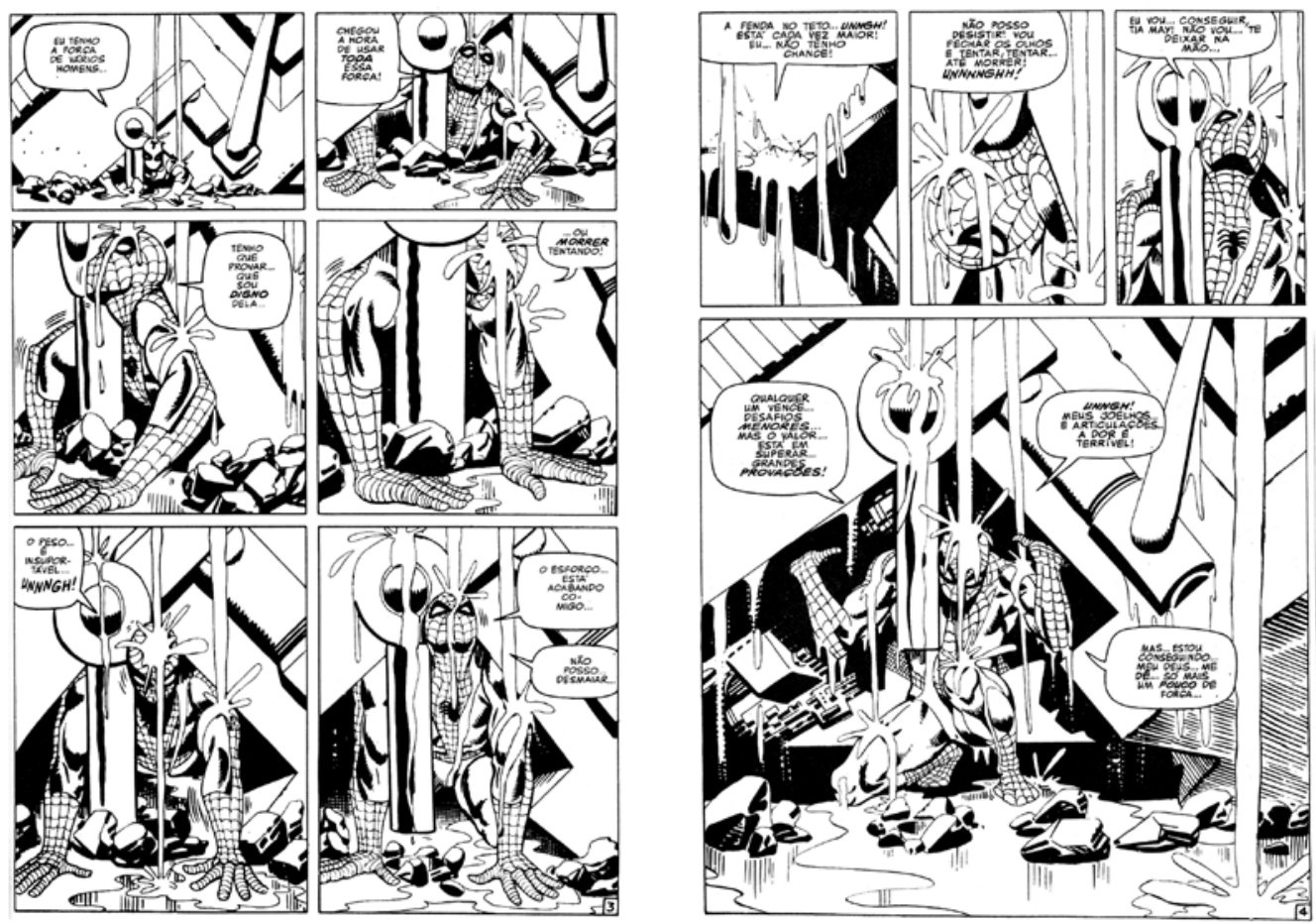

Figuras o3 e 04 - Sequência de “Capítulo Final”, com desenhos de Steve Ditko, no qual o Homem-Aranha luta para libertar-se de um "quase útero" e nascer novamente

Esta é uma história na qual a vida de Tia May está em jogo. Ela está à beira da morte num hospital e depende de um soro, o Iso36, que está na base secreta submarina do Doutor Octopus. O Homem-Aranha travou uma batalha com Octopus. O resultado foi que ficou preso sob uma enorme máquina de metal e o complexo submarino ameaça a ceder sob a pressão da água, que já goteja sobre o herói. Steve Ditko, com uma seqüência magistral de desenhos, mostra a luta do Homem-Aranha consigo mesmo para sair debaixo do terrível peso do metal que o prende. Já não 
é mais apenas a vida de Tia May que está em perigo, mas também a sua. Sentindo o peso da máquina de metal, a dor sobre o corpo, a água que vai aumentando cada vez mais, o tempo passando e corroendo a vida de Tia May, o herói luta com sentimentos contraditórios dentro de si mesmo: tem a visão do frasco com o Iso-36 à sua frente e isto lhe dá a esperança de cura para sua tia; ao mesmo tempo sente que pode fracassar, pois o peso é muito grande, e tem medo; lembra-se do tio que morreu por sua causa e sente um grande remorso que, se por um lado o abate, por outro é também o estímulo para que não seja responsável também pela morte de sua tia. Então brigando e falando consigo mesmo, com o volume de água aumentando, vai, pouco a pouco, levantando o pesadíssimo metal, até que numa arrancada final, "quando todos os seus músculos, tendões e ligamentos parecem prestes a estourar... quando a inconsciência parece inevitável... o Homem-Aranha triunfa" e consegue uma vitória dramática - que a página 5 da história expressa num desenho espetacular de Ditko -, não só levando o soro em tempo de salvar sua tia, mas também prendendo a quadrilha de Octopus que, entretanto, escapou.

A seqüência desta narrativa visual, como veremos, - pelas vidas ameaçadas, pela necessidade de libertação de um lugar que não é mais adequado à vida, pelos sentimentos contraditórios em função da possibilidade de mortes - é muito próxima da experiência do nascimento de um feto humano e da primeira forte aprendizagem da dinâmica de morte-renascimento, presente permanentemente na existência humana. Esta experiência está registrada, ao que parece, de forma intuitiva pelo artista e, porque está numa história em quadrinhos de caráter comercial, é oferecida a um grande número de leitores que podem entrar em contato com este conteúdo e elaborá-lo para sua própria vida. Certamente muitos leitores farão este movimento de forma inconsciente, mas o farão. Esta é mais uma "visualidade" que estará registrada no imenso manancial de imagens que estas pessoas terão consigo, à disposição para o processo de construção do si mesmo. Como veremos mais à frente, tal imagem, no entanto, tem um conteúdo bastante específico e poderá vir a ser um diferencial neste processo humano de desenvolvimento e formação. Na Figura 05, abaixo, o momento de libertação e vitória do Homem-Aranha, na pena de Steve Ditko: 


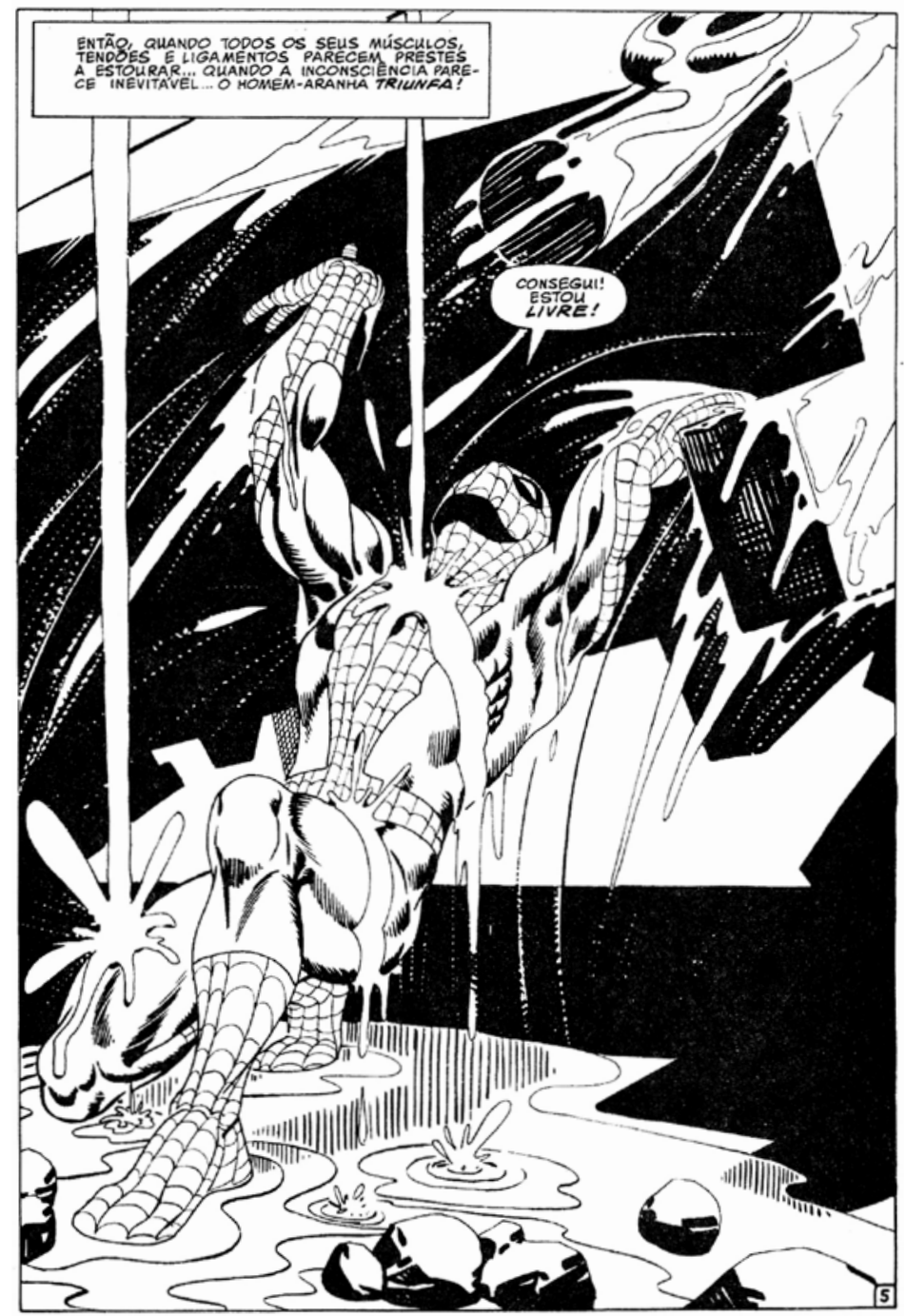

Figura o5 - A vitória dramática do Homem-Aranha no final da sequência desenhada por Ditko: vence a ameaça de morte, renasce para a vida

\section{A poética visual de Edgar Franco e uma história provocante: "Parto"}

Até aqui trouxe a referência de uma história em quadrinhos comercial bastante conhecida que, mesmo submetida aos férreos interesses do mercado editorial, consegue respirar autoralida- 
12. Apresentei no Congresso Intercom, na cidade de Natal em 2008, uma comunicação sobre o trabalho de Edgar Franco com o título "Transgressão, transcendência e esperança: os quadrinhos poético-filosóficos de Edgar Franco": http://intercom. org.br/papers/nacionais/20o8/ resumos/R3-0785-1.pdf.

13. Parte de seu trabalho de conclusão de curso está publicada sob o título "História em Quadrinhos e Arquitetura”. João Pessoa, Marca de Fantasia, 2004.

14. Sua dissertação de mestrado está publicada: "HQtrônicas: do suporte papel à rede internet" (2004).

15. Sua tese de doutorado intitula-se "Perspectivas Pós-humanas nas Ciberartes", defendida na ECA-USP, no ano de 2006 des graças à riqueza complexa do personagem e do universo com ele criado. Agora quero trazer outro tipo de narrativa e de construção visual. É uma história em quadrinhos que faz parte do universo ficcional criado por Edgar Franco e chamado por ele de "a aurora pós-humana"12. Edgar Franco nasceu na cidade de Ituiutaba, Minas Gerais, no ano de 1971. É graduado em Arquitetura $^{13}$ pela Universidade de Brasília, Mestre em Multimeios $^{14}$ pela Universidade Estadual de Campinas e Doutor em Artes ${ }^{15}$ pela Universidade de São Paulo. Além de professor e pesquisador na Faculdade de Artes Visuais da Universidade Federal de Goiás, Franco é também artista multimídia: com trabalhos de histórias em quadrinhos publicados, no Brasil e no exterior, em fanzines, álbuns, revistas, revistas independentes; tem HQtrônicas de sua autoria, roteiro e desenhos, publicados na internet e/ou em CDs; ilustrações para capas de livros e discos; desde 2007 entrou no campo da criação musical com a publicação de seu primeiro CD, "Posthuman Tantra", pela gravadora suíça Legatus Records e, em 2008 pela mesma gravadora, publicou o CD "Gothik Kama Sutra”. Como pesquisador tem livros, capítulos de livros, comunicações em congressos e assina uma coluna sobre histórias em quadrinhos, "Quadrinhos Redondos", no site Bigorna.
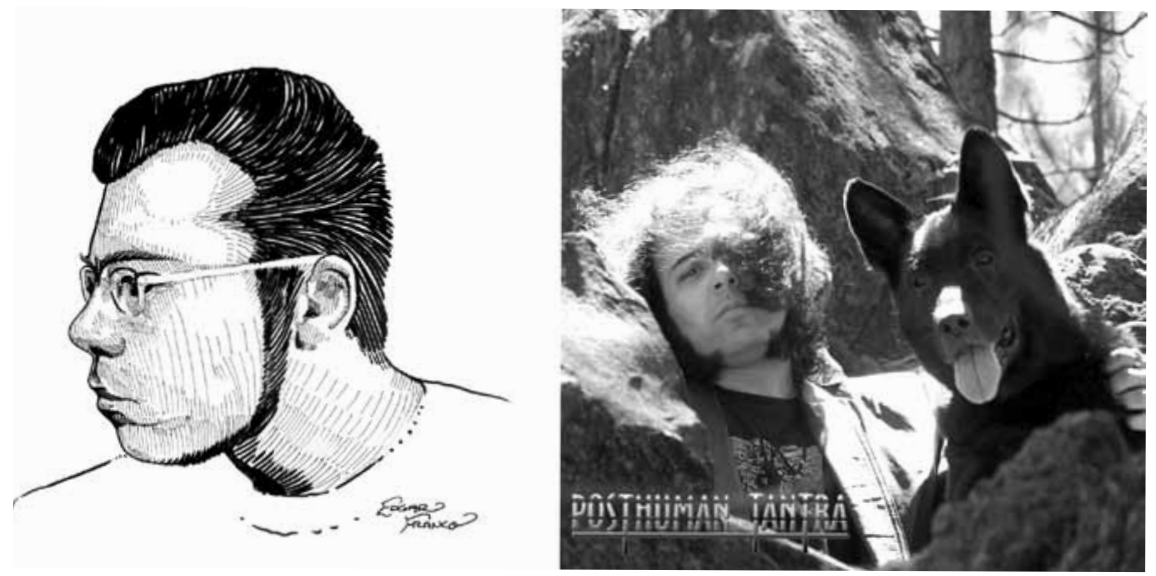

Figura o6 - Na primeira imagem Edgar Franco em auto-retrato, na segunda em foto para divulgar seu Posthuman Tantra

O trabalho produzido por Franco é autoral e pode ser compreendido no conjunto de uma obra de vários artistas brasileiros, pouco conhecidos do grande público, e que fazem um tipo de trabalho que vem sendo chamado por uns de quadrinhos poé- 
tico-filosóficos, por outros de quadrinhos fantástico-filosóficos ou ainda simplesmente quadrinhos poéticos. A história "Parto" é, portanto, uma história em quadrinhos poético-filosófica que se desenvolve em cinco páginas, dentro do universo pós-humano criado pelo autor. Neste universo a tecnologia está tão desenvolvida que novas condutas culturais vão se estabelecendo: desde sofisticadas próteses tecnológicas implantadas no corpo humano até o transporte da consciência humana para máquinas, passando pela substituição, também tecnológica, de processos até então tidos como "naturais" pelos seres humanos, como é o caso, por exemplo, do parto. Daí toda a discussão sobre a pós-humanidade. A figura 7 , a seguir, é a ilustração da página 4 da história em quadrinhos de Edgar Franco.

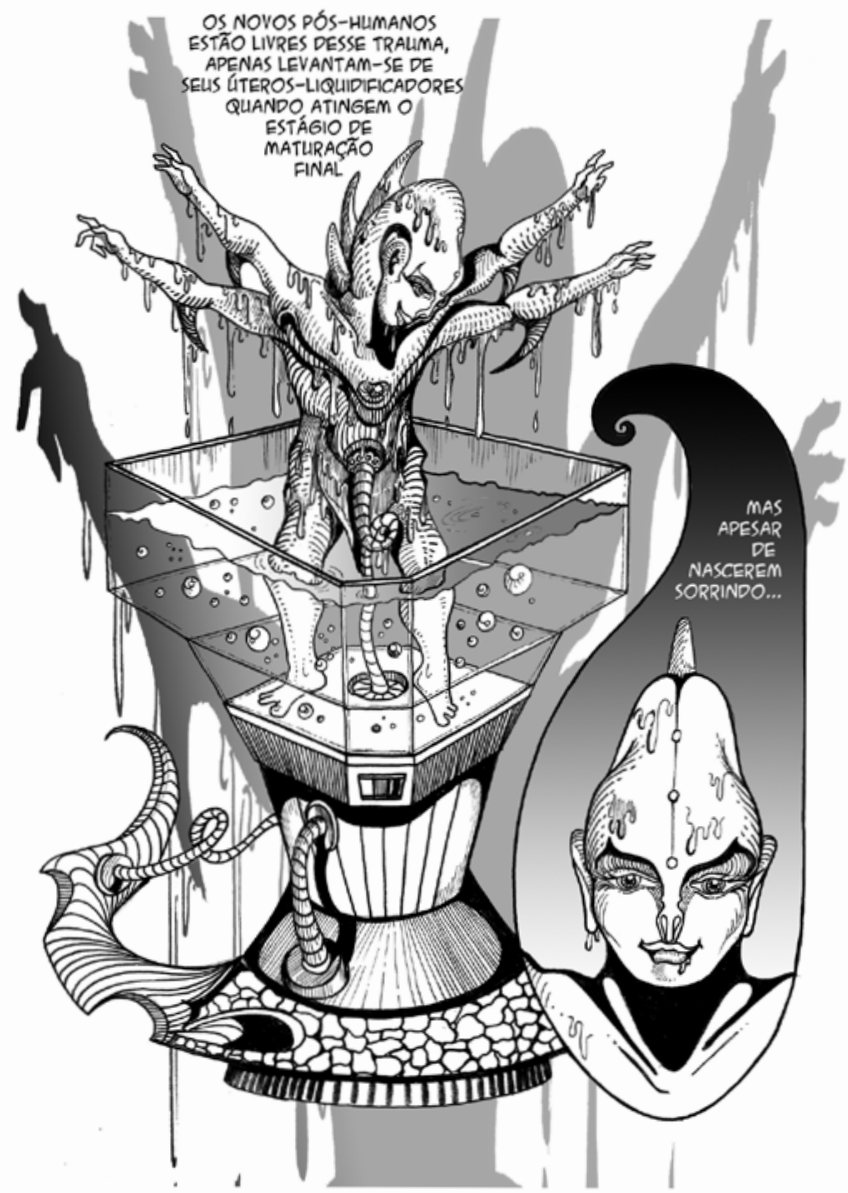

Figura 07

Desenho de Edgar Franco para a página 4 de sua história "Parto", mostrando o nascimento póshumano não mais com dor, mas com a "suavidade" tecnológica. 
Figuras o8 e o9 O trauma do parto natural e o futuro, sem as dores do parto
A poética visual de Franco é bem distinta da Ditko. No caso da história "Parto" é uma história curta, onde cada página se identifica com um requadro. No entanto, cada requadro tem uma forma diferente: na página 1 tem a forma de uma borboleta; na página 2 as linhas retas de uma máquina fundem-se com as curvas de um corpo feminino em gestação, com claro destaque ao coração e ao útero; na página 3 são as pernas abertas da mulher, no momento do parto, que praticamente definem os limites do requadro; na página 4 o centro definidor é o útero-liquidificador e há o recurso de um close no rosto do feto, que já não nasce chorando, mas sim sorrindo; finalmente, na página 5 , os limites do requadro são a "sombra de uma grande cabeça" no centro da qual está um ser feminino, com "muitos" olhos, suspenso entre um coelho com asas (o medo?) e uma serpente também com asas (a transformação?). Os desenhos têm uma marca de sofisticação, leveza e sensualidade, incorporando muitos motivos simbólicos: mãos, embrião, casulo, borboleta, cordões umbilicais, seios, úteros, vagina, fetos, coração, asas, masculino, feminino, máquinas, cosmos, coelho, serpente, etc. O simbólico é sempre uma porta aberta para a criação poética e, neste sentido, o trabalho de Franco é um forte convite à co-autoria do leitor que se vê provocado também por uma inescapável reflexão sobre o sofrimento humano e a tecnologia. As Figuras o8 e 09, desenhos de Franco, reproduzem as páginas 3 e 5 de sua história respectivamente.

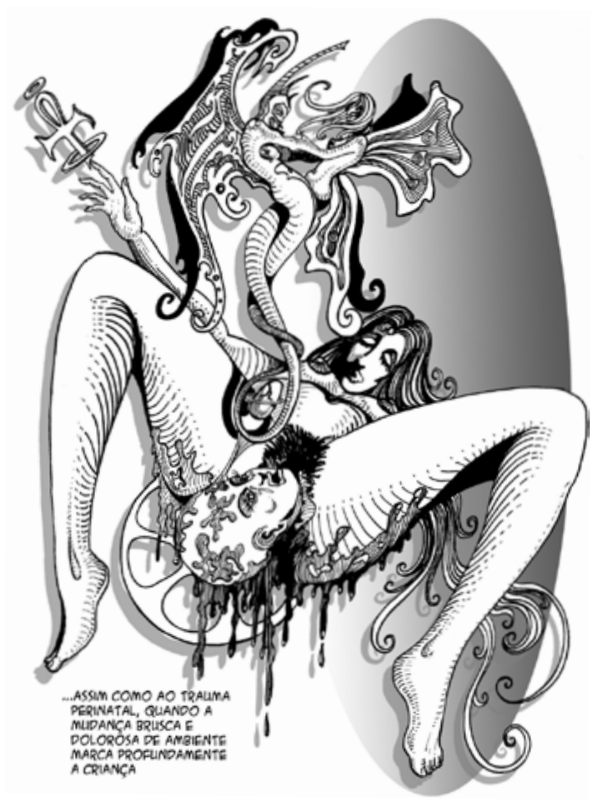

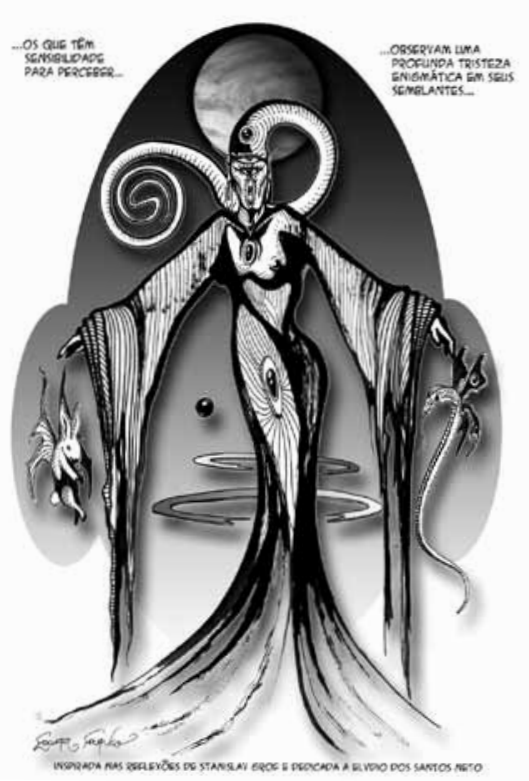




\section{Stanislav Grof e a experiência perinatal.}

Stanislav Grof tem investigado a consciência humana por meio dos estados ampliados de consciência, estados obtidos inicialmente com o uso do ácido lisérgico (LSD) e, posteriormente, com a respiração holotrópica. Já em suas primeiras pesquisas, na década de 1950, registrou e gravou em fitas magnéticas os conteúdos elaborados pelos sujeitos de sua investigação. Coletou tais relatos, catalogou-os, organizou-os e ousou uma nova interpretação que vai além do inconsciente pessoal como proposto por Freud. A cartografia que propôs não é oriunda de estudos teológicos que tomam como ponto de partida a revelação de livros sagrados, e nem tampouco de pura especulação filosófica e metafísica. É fruto de suas investigações com os estados ampliados de consciência e, portanto, tem uma base empírica. Esta cartografia distingue quatro níveis na consciência (ver figura 10): a barreira sensorial, o nível biográfico-rememorativo, o nível perinatal e o nível transpessoal. Para este trabalho interessa-nos especialmente o nível perinatal.

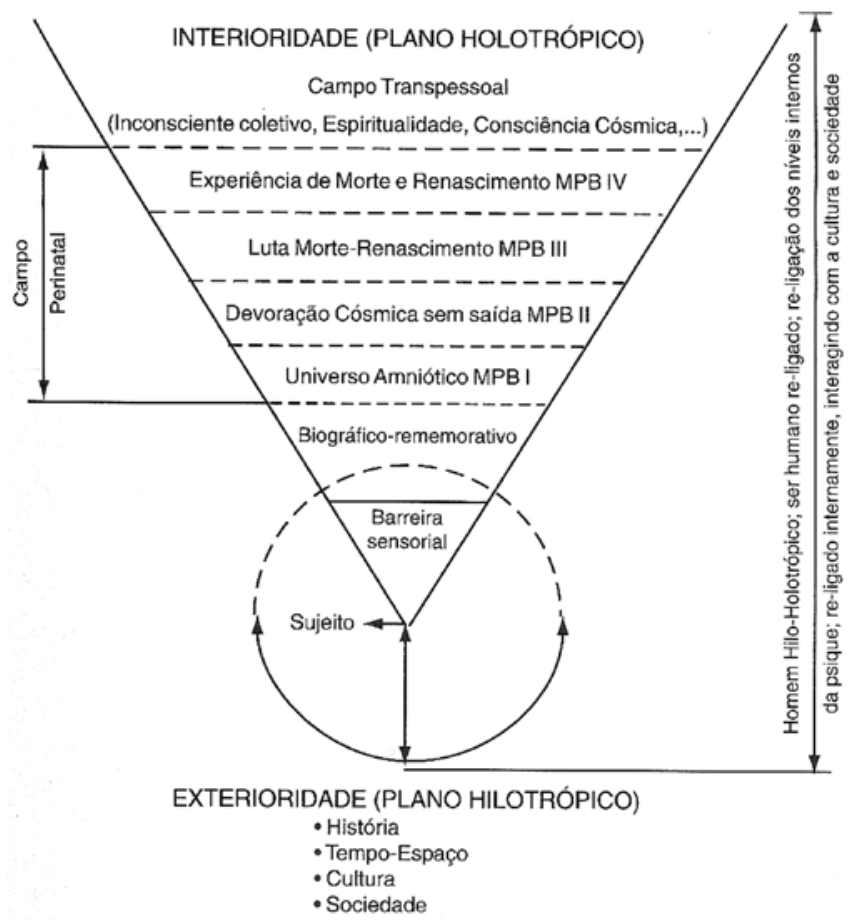

ESBOÇO DA CARTOGRAFIA INTERNA SEGUNDO STANISLAV GROF

(Homem Hilo-Holotrópico, Antropologia da Inteireza)
Figura 10

Fonte: "Por uma Educação Transpessoal", livro do autor deste artigo 
Figura 11 Os quatro momentos do parto natural em desenho do próprio Stanislav Grof que, segundo o autor, instituem o campo perinatal de cada indivíduo que assim nasce. Fonte: O livro "Além do Cérebro" de Stanislav Grof
O terceiro nível, o perinatal, diz respeito à memória e ao aprendizado experimentado por ocasião do processo de nascimento dos seres humanos, processo este que Grof chama de morte-renascimento, por toda dramaticidade e risco que traz. Sua cartografia sugere a existência, no nível perinatal, de quatro matrizes de aprendizado que se constituem neste momento e que, embora permaneçam inconscientes, atuam na vida pós-uterina, interferindo na definição de nossas características pessoais e no processo de construção de nossa identidade. Grof sugere que experiências de muita dor e sofrimento numa dessas matrizes podem fazer com que o sujeito em questão guarde com esta matriz uma relação negativa, Matriz Negativa, e afirma que "muitas observações sobre o indivíduo que está sob forte influência de matrizes perinatais negativas sugerem que ele encara a vida e seus problemas de um modo não somente vazio, mas com conseqüências destrutivas para si e para os outros, a longo prazo" (1987, p. 307-308). Entretanto, afirma também que tais experiências podem ser acessadas (criou um processo para isto: a Respiração Holotrópica) e liberadas tornando a vida do sujeito mais adequada ao desenvolvimento pleno. Por sua vez a experiência positiva vivida no útero e no processo de nascimento ajudam a preparação, desde os primeiros instantes da vida, para a vivência da "tempestuosa busca de ser".

No campo perinatal (ver Figura 11) Grof detectou a titânica luta do feto pela vida: ameaçado pela morte, no processo doloroso do parto, ele luta para sobreviver. Simbolicamente pode-se dizer que tal processo é uma "descida aos infernos" e uma "subida para ressurreição": morte e renascimento. Assim, logo ao nascer aprendemos uma importante lição: existe uma dinâmica de morte e renascimento que perpassa os movimentos de evolução

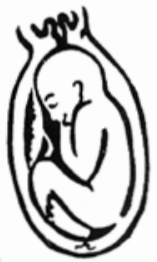

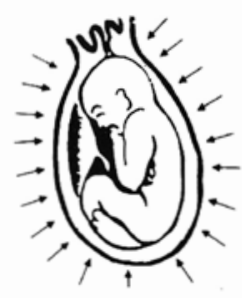

1

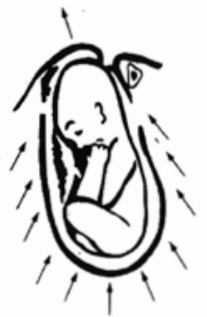

2

3 
da vida. Compreender a vida assim significa trazer a necessidade de educar os seres humanos para o processo morte-renascimento: morrer para as concepções estáticas e imobilizadoras de vida; renascer para processos que auxiliem a caminhar para frente, rumo ao amadurecimento e à plenitude.

Fica mais claro, a partir daqui, porque me chamou a atenção a seqüência desenhada por Ditko, como fica mais clara também a motivação para trazer a história em quadrinhos "Parto", de Edgar Franco.

\section{Ditko, Franco e o sofrimento humano: entre o super-herói e a tecnologia.}

Ditko e Franco, mediante duas poéticas visuais diferentes, nos oferecem oportunidade de refletir acerca de um mesmo problema: o sofrimento e os processos de morte-renascimento na vida humana. Ditko representa este processo na vida de um superherói e Franco pelas transformações favorecidas pelo sofisticado desenvolvimento científico e tecnológico da humanidade.

O herói de Lee/Ditko, apesar de ser super-herói, não escapa do sofrimento. Também ele, apesar da força de muitos homens, tem medo, dúvida, remorso, culpa, raiva, desânimo, esperança e desesperança. Também ele precisa lidar com suas contradições, fragilidades e enfrentar o processo de morte-renascimento. É possível pensar que o Homem-Aranha/Peter Parker não tenha saído o mesmo depois daquele episódio. Saiu renascido, apesar das marcas da dor e do sofrimento. Ganhou nova vida, novas perspectivas. Uma experiência daquele tipo é algo transformador. Não se sai dela da mesma maneira com que se entrou. $\mathrm{O}$ ser "morre" e "renasce", transformado.

O feto da história em quadrinhos de Franco nasce de um úteroliquidificador. O seu nascimento é apenas um levantar-se, tendo chegado o momento da maturação. A tecnologia superou a necessidade de viver o processo de "morte-renascimento" daqueles que vêm a luz. Primeiro Otto Rank e depois Stanislav Grof nos ensinaram que o trauma do parto tem sido um momento importante para constituição do ser humano. Nele aprendemos o processo doloroso de morte e renascimento. A vida é um permanente movimento que supõe saber morrer para o que já passou e saber nascer para o novo que está nascendo ou renascendo. Este aprendizado, contudo, é feito na dor. Será possível abolir este processo? Será possível eliminar a dor? Será desejável? Qual 
o limite aceitável da dor? Eliminar a dor seria eliminar nosso aprendizado para enfrentar a construção da existência?

No mundo futuro talvez não seja mais característica dos partos o choro das crianças, que morreram para a vida do útero e nasceram para a vida nas culturas e sociedades humanas. Talvez elas nasçam sorrindo uma vez chegadas à maturação. Talvez não corram mais os riscos de um "berço ruim" como no útero antigo. Mas haverá para elas a possibilidade de conhecer a alegria e a serenidade da vitória de quem trilhou o caminho entre a morte e o renascimento? Ou haverá "uma profunda tristeza enigmática em seus semblantes"? O que queremos? O que estamos fazendo?

Duas poéticas visuais diferentes e uma linguagem, as histórias em quadrinhos, que possibilitam uma reflexão filosófica e ética sobre o lugar do sofrimento no processo de fazer-se do ser humano. Dois bons "textos" para uma viagem narrativa. Dois bons "pretextos" para uma reflexão sobre a condição humana. Reflexão necessária para construir respostas para estas perguntas: $\mathrm{O}$ que queremos? O que estamos fazendo?

\section{Considerações finais}

Alguns dirão que as histórias em quadrinhos são apenas um tipo de entretenimento e lazer e que, por certo, não se prestam a reflexões mais profundas. Outros dirão que ela facilita o processo de comunicação e, portanto, são didáticas e devem ser utilizadas nos processos pedagógicos, formais e não-formais, ainda que corram o risco de superficialização.

Entendo que as histórias em quadrinhos são também uma forma de entretenimento e lazer, mas não só. Elas têm também um poder didático, mas não só. Elas, como arte e comunicação, têm valor em si. São mais do que entretenimento e lazer. Várias delas não são nada didáticas, enquanto facilitadoras da comunicação, mas, pelo contrário, são problematizações provocadoras que fazem pensar e nem sempre apresentam respostas. Muitas, é verdade, são comerciais e fazem-se para um abstrato cidadão mediano, com gostos e padrões bem identificados. Outras, no entanto, são narrativas e poéticas visuais de andarilhos humanos implicados com a própria condição e necessitados de dizer algo ao mundo e aos demais humanos. Fazem-se contra e apesar do mercado. Entre estes "andarilhos", que criam visualidades poderosas, há aqueles que con- 
seguiram dobrar as "leis editoriais" e chegam, em fino estilo, ao grande público. Enfim, estamos diante de uma linguagem que não pode ser desprezada. As narrativas visuais de Ditko e Franco sugerem que elas podem favorecer reflexões profundas sobre o viver, $o$ sofrer, a construção de sentido e o desenvolvimento de uma boa energia a favor da existência pessoal e coletiva.

Se elas, pelo poder de sua narrativa visual, nos ajudam a simbolizar, autoral ou comercialmente, a complexidade de nossos mundos, então porque não considerá-las? Afinal, o que queremos? $\mathrm{O}$ que estamos fazendo?

\section{Referências Bibliográficas}

ALVES, Rubem. Mahatma Gandhi: a política dos gestos poéticos. São Paulo: Brasiliense, 1983. 119p.

COSTA, Maria Cristina Castilho. Ficção, Comunicação e Mídias. São Paulo: Senac, 2002.

COSTA, Marisa Vorraber. Poder, discurso e política cultural: contribuições dos Estudos Culturais ao campo do currículo. In: LOPES, Alice Casimiro; MACEDO, Elizabeth (Orgs.). Currículo: debates contemporâneos. São Paulo: Cortez, 2002. p. 133-149.

DITKO, Steve; LEE, Stan. O capítulo final. In: MARVEL COMICS. As primeiras aventuras do Homem-Aranha. Número 8. São Paulo: Editora Abril, 1997. 20 p.

FRANCO, Edgar. HQtrônicas: do suporte papel à rede internet. São Paulo: Annablume: Fapesp, 2004. 284 p.

- Parto. In: Arlectos e Pós-humanos, no 2, 2007, Jaú/SP: SM Editora, p. 3-7.

GIROUX, Henry. Escola crítica e política cultural. 3ed. São Paulo: Cortez: Autores Associados, 1992. 104 p.

MARTINS, Joel. Um enfoque fenomenológico do currículo: educação como poíesis. São Paulo: Cortez, 1992, p. 142. 
MARTINS, Mirian Celeste; PICOSQUE, Gisa; GUERRA, M. Terezinha Telles. Didática do Ensino da Arte: a língua do mundo: poetizar, fruir e conhecer arte. São Paulo: FTD, 1998. 198 p.

SANTOS NETO, Elydio dos. Educação Transpessoal: a dinâmica do pessoal e do transpessoal na ação pedagógica e na formação de professores a partir do pensamento de Stanislav Grof. São Paulo: PUC-SP, 1998 (Tese de Doutorado em Educação).

Por uma Educação Transpessoal: a ação pedagógica e o pensamento de Stanislav Grof. Rio de Janeiro/São Bernardo do Campo: Lucerna/Metodista, 2006, p. 110.

GROF, Stanislav. Além do Cérebro: Nascimento, Morte e Transcendência em Psicoterapia. São Paulo: McGraw-Hill, 1987,p. 327.

WOLK, Douglas. Reading Comics: how graphic novels work and what they mean. United States: Da Capo Press, 2007, p. 405. 


\section{ELYDIO DOS SANTOS NETO \\ É graduado em Filosofia (1982), em Pedagogia (1982), Mestre em Ciências da Religião pela PUC-SP (1993) e Doutor em Edu- cação pela PUC-SP (1998). É docente-pesquisador do Progra- ma de Mestrado em Educação da Universidade Metodista de São Paulo onde leciona a disciplina "Formação de Educadores e Cultura Visual". Coordenador do Grupo de Estudos e Pesquisa Paulo Freire (GEPF-UMESP). Participa do Grupo de Pesquisa INTERESPE. Participa do Observatório de Quadrinhos da USP. Autor de "Por uma Educação Transpessoal" e de trabalhos so- bre historias em quadrinhos apresentados em congressos. \\ E-mails: elydio@gmail.com; elydio.santos@metodista.br.}

